\title{
BDNF and the Antidepressant Effects of Ketamine and Propofol in Electroconvulsive Therapy: A Preliminary Study
}

This article was published in the following Dove Press journal: Neuropsychiatric Disease and Treatment

\author{
Xing-Bing Huang \\ Xiong Huang \\ Hong-Bo $\mathrm{He}$ \\ Fang Mei \\ Bin Sun \\ Su-Miao Zhou \\ Su Yan \\ Wei Zheng \\ Yuping Ning
}

The Affiliated Brain Hospital of Guangzhou Medical University (Guangzhou Huiai Hospital), Guangzhou, People's Republic of China
Correspondence: Yuping Ning; Wei

Zheng

36 Mingxin Road, Liwan District,

Guangzhou, People's Republic of China

Tel +86-13322214239; +86-133222I 4239

Fax +86-20-8I891391; +86-20-81778169

Email ningjeny@126.com;

zhengwei0702@163.com
Objective: Ketamine and propofol have become increasingly popular in electroconvulsive therapy (ECT) anaesthesia. This study was conducted to examine whether changes in serum levels of brain-derived neurotrophic factor (BDNF) are associated with the antidepressant effects of ketofol, a combination of ketamine and propofol, in ECT for patients with treatment-resistant depression (TRD).

Methods: Thirty patients with TRD (18-65 years) were enrolled and underwent eight ECT sessions with ketamine $(0.5 \mathrm{mg} / \mathrm{kg})$ plus propofol $(0.5 \mathrm{mg} / \mathrm{kg})$ (ketofol). Symptom severity was monitored using the 17-item Hamilton Depression Rating Scale (HAMD-17) and the Brief Psychiatric Rating Scale (BPRS), and serum levels of BDNF were examined by enzyme-linked immunosorbent assay (ELISA) at baseline and after 2, 4, and 8 ECT treatments. Serum levels of BDNF were also collected from thirty healthy controls.

Results: At baseline, there were no significant differences in serum levels of BDNF between patients with TRD and healthy controls. The response and remission rates in patients with TRD were 100\% (30/30) and 53.3\% (16/30) after ECT treatment, respectively. Despite a significant reduction in HAMD-17 and BPRS scores after ECT, no changes in serum levels of BDNF were observed after ECT treatment when compared to baseline. No association was found between serum levels of BDNF and changes in illness severity.

Conclusion: Serum levels of BDNF did not represent a suitable candidate biomarker for determining the antidepressant effects of ketofol during ECT for patients with TRD.

Keywords: BDNF, ketamine, propofol, electroconvulsive therapy, treatment-resistant depression

\section{Introduction}

Electroconvulsive therapy (ECT) is associated with rapid clinical improvement for severe or refractory major depressive disorder (MDD), with a remission rate of $87 \%{ }^{1}$ Intravenous anaesthetic medication, such as propofol, ketamine, methohexital, and thiopental, is administered before ECT to minimize the induction of tonic-clonic seizure related adverse events and subjective unpleasantness. ${ }^{2}$ A recent meta-analysis found that ketamine combined with other anaesthetic agents could confer a short-term advantage in the improvement of depressive symptoms at the early stages of ECT. ${ }^{2}$

The ketamine and propofol combination (ketofol) could be an alternative strategy to enhance the seizure quality and clinical efficacy of ECT. ${ }^{3}$ Notably, while ketofol is not an actual product, it has been used in previous studies. ${ }^{4}$ In stressed rats undergoing ECT, ketofol played an important role in enhancing antidepressant 
efficacy and ameliorating neurocognitive impairment. ${ }^{5}$ Wang et al found that ketofol was superior in improving depressive symptoms over propofol alone and was associated with fewer adverse events than ketamine alone, suggesting that ketofol should be considered as the firstchoice anaesthesia in patients with MDD undergoing ECT. $^{3}$

The neurobiological mechanisms underlying the antidepressant effects of ketofol anaesthesia in ECT are complex and not fully understood. For example, in an animal study, ECT was reported to increase brain derived neurotrophic factor (BDNF) levels in the parietal cortex, hippocampus, neostriatum, entorhinal cortex, frontal cortex, and septum. ${ }^{6}$ However, another study found that plasma BDNF levels appeared to be an unsuitable candidate biomarker for predicting the antidepressant efficacy of ECT. ${ }^{7}$

Numerous studies have implicated BDNF in the pathophysiology of MDD and the antidepressant response. ${ }^{8}$ Patients with MDD had lower serum levels of BDNF than healthy controls. ${ }^{8,9}$ A large number of prior studies, ${ }^{9,10}$ although not all of them, ${ }^{11}$ found that this deficit was reversed in those who obtained successful antidepressant treatment. Interestingly, remitted MDD patients showed elevated BDNF levels, that were negatively correlated with the severity of depressive symptoms. ${ }^{12}$

A growing number of meta-analyses ${ }^{13-15}$ consistently concluded that ketamine had rapid antidepressant effects in patients with treatment refractory depression (TRD). The antidepressant effects of ketamine could be attributed to its role in enhancing glutamatergic transmission by a chain of neurobiological events, such as a rapid increase in BDNF levels. ${ }^{16}$ However, the association between the rapid antidepressant effects of ketofol anaesthesia in ECT and the changes in serum levels of BDNF is unclear.

In the present study, patients with TRD were administered ketofol during ECT. We hypothesized that compared to healthy controls, serum levels of BDNF would be lower in patients with TRD and that the antidepressant effects of ketofol anesthesia during ECT would be correlated with increased serum levels of BDNF in patients with TRD.

\section{Methods}

\section{Participants and Study Procedures}

The study was approved by the ethics committee of the Affiliated Brain Hospital of Guangzhou Medical University (approval number: 2013020), and it was undertaken from February 2013 to December 2013. This study was conducted in accordance with the Declaration of Helsinki. All participants were recruited from the wards of the Affiliated Brain Hospital of Guangzhou Medical University and signed written informed consent before participation.

Adult patients (18-65 years) who fulfilled the diagnostic criteria of the International Statistical Classification of Diseases and Related Health Problems, 10th revision (ICD-10) for MDD with a current major depressive episode. As recommended by the previous study, ${ }^{17}$ TRD was defined as the failure to respond to at least two adequate antidepressant trials for more than four weeks in the current episode. Furthermore, all TRD patients with severe depressive symptoms at screening, as determined by a 17-item Hamilton Depression Rating Scale score (HAMD-17) $\geq 20$, were recruited. ${ }^{18}$ The exclusion criteria for this study were as follows: (1) any other serious mental disorder meeting ICD-10 diagnostic criteria, including schizophrenia, dementia, anxiety and personality disorders; (2) current organic brain disease or severe physical illness; (3) a history of seizures; (4) current alcohol or substance abuse; (5) lactating or pregnant; and (6) other contraindications for ECT or anaesthesia.

Thirty healthy individuals, who were matched for age and sex to the patients, were enrolled from the local community during the same period. None of them had serious physical diseases, or alcohol or other substance abuse/ dependence except for nicotine.

\section{Treatment}

The patients with TRD received ketamine plus propofol as anaesthesia during ECT. During the study period, they were not prescribed any antipsychotics or antidepressants. First, each subject was intravenously administered atropine sulfate $(1 \mathrm{mg})$. Then, they received the combination of propofol $(0.5 \mathrm{mg} / \mathrm{kg})$ and ketamine $(0.5 \mathrm{mg} / \mathrm{kg})$ as anaesthesia. After the induction of anaesthesia, succinylcholine $(1 \mathrm{mg} / \mathrm{kg})$ was intravenously administered as a muscle relaxant.

The patients with TRD received consecutive bilateral ECT sessions three times a week for a total of 8 sessions using Thymatron ${ }^{\circledR}$ IV device (Somatics LLC, Lake Bluff, Illinois, USA). The seizure threshold of each recruited subject was calculated according to the half-age method (\% energy=half the age) ${ }^{19}$ Vital signs, including blood 
pressure, were recorded before anaesthesia and $10 \mathrm{~min}$ after the ECT procedure.

\section{Clinical Assessment}

Depressive and psychotic symptoms at baseline, after treatments two, four, and six (on the mornings of the next scheduled ECT) and 48-72 h after the last (treatment eight) treatment were assessed as measured by the HAMD-17 and the Brief Psychiatric Rating Scale (BPRS) ${ }^{20}$ respectively. Response and remission were defined as at least $50 \%$ reduction from the baseline HAMD-17 scores and HAMD-17 scores $\leq 7$, respectively, following the methodology of a prior study. ${ }^{21}$

\section{Serum Levels of BDNF}

For the depression cohort, serum was collected, and the depression scales were administered at the same time points. For the healthy controls, a single serum sample was collected when the individuals were recruited in this study. Serum was collected and stored at $-80{ }^{\circ} \mathrm{C}$ until analysis. Following the manufacturer's instructions, serum levels of BDNF were examined by enzyme-linked immunosorbent assay (ELISA) (BDNF Emax Immunoassay System, Promega, USA). BDNF levels were determined by absorbance at $450 \mathrm{~nm}$ wavelength using optical density values based on the standard curve values.

\section{Statistical Analysis}

Demographics and clinical variables were compared between patients with TRD and healthy controls at baseline using the chi-square test, Fisher's exact test, Student's $t$-test, or Mann-Whitney $U$-test, as appropriate. Similarly, baseline demographics and clinical variables were compared between the remitters and non-remitters, who were defined based on the HAMD-17 scores after completing the last ECT treatment using chi-square test, Fisher's exact test, Student's $t$-test, or Mann-Whitney $U$-test, as appropriate. Serum levels of BDNF, HAMD-17 scores and BPRS scores were compared between remitters and nonremitters at each assessment time point using linear mixed model analysis. Pearson's bivariate correlation analysis was utilized to investigate the correlation between the reduction in HAMD-17 and BPRS scores and the change in serum levels of BDNF in patients with TRD. The level of significance was set at $p<0.05$.

\section{Results}

\section{Participant Characteristics}

At baseline, there were no significant differences in serum levels of BDNF between patients with TRD and healthy controls $(p>0.05)$ (Supplemental Table 1 and Supplemental Figure 1). No significant differences were found between remitters and non-remitters with regard to sex, age, baseline HAMD-17 and BPRS scores, or baseline serum levels of BDNF (all $p>0.05$ ) (Table 1).

\section{Treatment Remission and BDNF}

The rates of response and remission were 100\% (30/30) and $53.3 \%$ (16/30) after ECT treatment, respectively. A significant reduction in depressive symptoms (Figure 1) and psychotic symptoms (Supplemental Figure 2) was found after ECT treatment. Serum levels of BDNF, baseline HAMD-17 scores and BPRS scores did not differ between remitters and nonremitters (all $p>0.05$ ) (Table 1). Supplemental Table 2

Table I Characteristics of the Remitters and Non-Remitters After ECT

\begin{tabular}{|l|l|l|l|l|l|l|l|l|l|}
\hline \multirow{2}{*}{ Variables } & \multicolumn{2}{|l|}{ Total Sample (n=30) } & \multicolumn{2}{l|}{ Remitters (n=16) } & \multicolumn{2}{l|}{ Non-Remitters (n=14) } & \multicolumn{2}{l|}{ Statistics } \\
\cline { 2 - 10 } & $\mathbf{N}$ & $\%$ & $\mathbf{N}$ & $\%$ & $\mathbf{N}$ & $\%$ & $X^{\mathbf{2}}$ & $\mathbf{d f}$ & $\mathbf{p}$ \\
\hline Male & 12 & 40.0 & 6 & 37.5 & 6 & 42.9 & 0.1 & 1 & 0.77 \\
Employed & 22 & 73.3 & 13 & 81.3 & 9 & 64.3 & $-^{\mathrm{a}}$ & $-^{\mathrm{a}}$ & 0.42 \\
Married & 23 & 76.7 & 13 & 81.3 & 10 & 71.4 & $-^{\mathrm{a}}$ & $-^{\mathrm{a}}$ & 0.68 \\
\hline & Mean & SD & Mean & SD & Mean & SD & T & df & P \\
\hline Age (Years) & 30.4 & 9.6 & 29.3 & 8.3 & 31.7 & 11.0 & -0.7 & 28 & 0.50 \\
Baseline Serum levels of BDNF (ng/mL) & 23.3 & 6.1 & 22.9 & 6.9 & 23.7 & 5.2 & -0.4 & 28 & 0.72 \\
Baseline HAMD-I7 scores & 26.7 & 2.0 & 27.0 & 1.8 & 26.4 & 2.2 & 0.9 & 28 & 0.38 \\
Baseline BPRS scores & 36.5 & 5.2 & 35.4 & 3.2 & 37.8 & 6.6 & -1.3 & 28 & 0.22 \\
\hline
\end{tabular}

Note: ${ }^{\text {a}}$ Fisher's exact test.

Abbreviations: BDNF, brain-derived neurotrophic factor; BPRS, the Brief Psychiatric Rating Scale; df, degrees of freedom; ECT, electroconvulsive therapy; HAMD-I7, the 17-item Hamilton Depression Rating Scale; SD, standard deviation. 


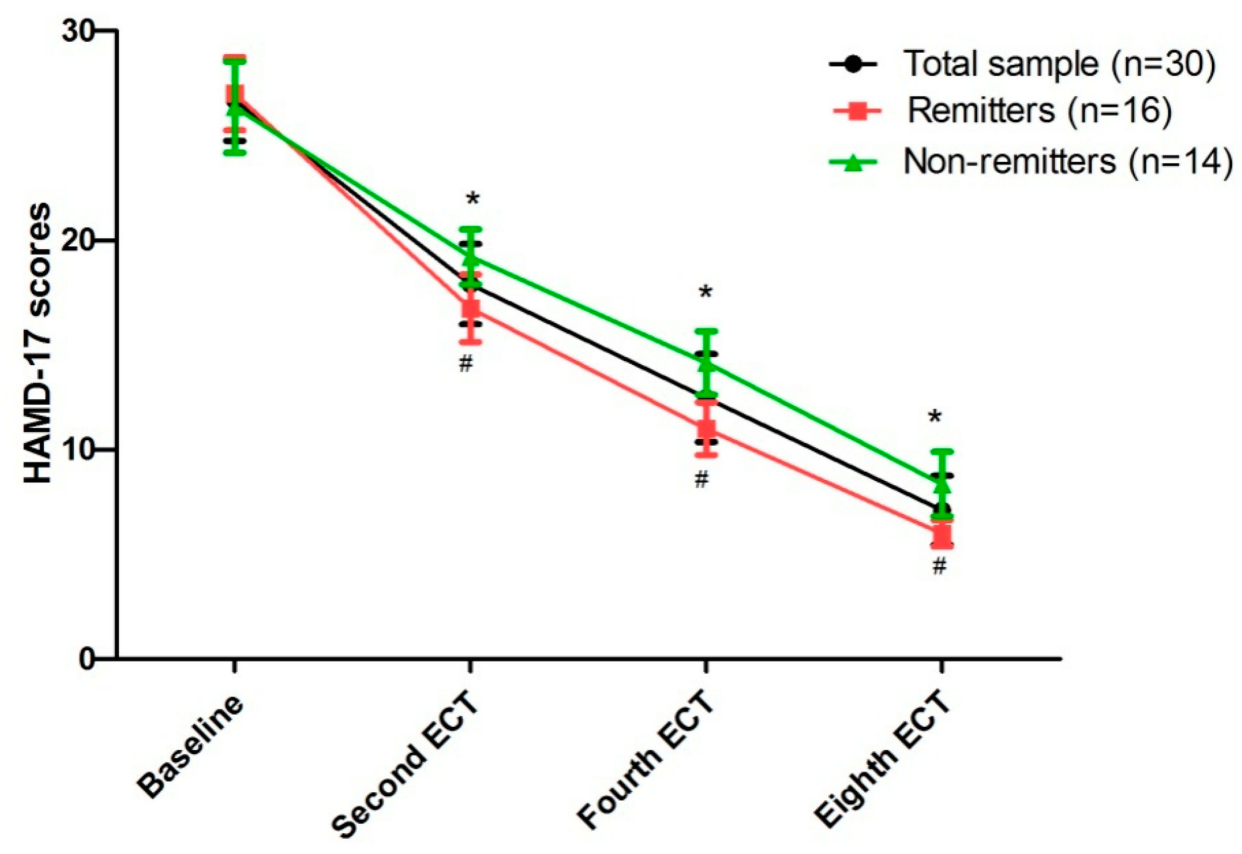

Figure I Change in depressive symptoms following eight ECT sessions in patients with treatment refractory depression.

Notes: *Significant difference was found at indicated times when compared baseline $(p<0.05)$, "Significant difference was found between remitters and non-remitters at indicated times $(p<0.05)$.

Abbreviations: ECT=electroconvulsive therapy; HAMD-17=the 17-item Hamilton Depression Rating Scale.

presents the comparison of serum levels of BDNF, HAMD-17 scores and BPRS scores between remitters and non-remitters at each time point.

Linear mixed models were utilized to compare serum levels of BDNF, HAMD-17 scores and BPRS scores over time in remitters and non-remitters (Table 2). Both HAMD17 and BPRS scores showed significant main effects of group (HAMD-17 scores: $\mathrm{F}=18.2, p<0.001$; BPRS scores: $\mathrm{F}=5.2$, $p=0.03$ ) and time (HAMD-17 scores: $\mathrm{F}=1289.1, p<0.001$; BPRS scores: $\mathrm{F}=202.4, p=0.03$ ) (Table 2). Serum levels of

Table 2 Comparisons of Serum Levels of BDNF, HAMD-17 Scores, and BPRS Scores Between Remitters and NonRemitters Using Linear Mixed Model Analysis

\begin{tabular}{|c|c|c|c|c|c|c|}
\hline \multirow[t]{2}{*}{ Variable } & \multicolumn{2}{|c|}{$\begin{array}{l}\text { Group-by- } \\
\text { Time } \\
\text { Interaction }\end{array}$} & \multicolumn{2}{|c|}{$\begin{array}{l}\text { Time Main } \\
\text { Effect }\end{array}$} & \multicolumn{2}{|c|}{$\begin{array}{l}\text { Group Main } \\
\text { Effect }\end{array}$} \\
\hline & $\mathbf{F}$ & $p$ & $\mathbf{F}$ & $p$ & $\mathbf{F}$ & $p$ \\
\hline HAMD-I7 scores & 8.3 & $<0.001$ & 1289.1 & $<0.001$ & 18.2 & $<0.001$ \\
\hline $\begin{array}{l}\text { Serum levels of } \\
\text { BDNF }\end{array}$ & 0.8 & 0.51 & 2.8 & 0.05 & 0.5 & 0.48 \\
\hline BPRS scores & 1.8 & 0.19 & 202.4 & $<0.001$ & 5.2 & 0.03 \\
\hline
\end{tabular}

Note: Bolded values are $p<0.05$.

Abbreviation: BDNF, brain-derived neurotrophic factor; BPRS, the Brief Psychiatric Rating Scale; HAMD-17, the 17-item Hamilton Depression Rating Scale.
BDNF showed no significant main effects of group, time or group-by-time interaction (all $p>0.05$ ) (Table 2 ). No significant difference in serum levels of BDNF between remitters and non-remitters at any of the assessment time points was found (all $p>0.05$ ) (Figure 2 and Supplemental Table 2). Similarly, no significant difference in serum levels of BDNF was found at any assessment time point when compared with baseline (all $p>0.05$ ) (Figure 2).

\section{Relationship Between Serum Levels of BDNF and Symptom Severity}

Baseline serum levels of BDNF were not significantly correlated with baseline HAMD-17 $(\mathrm{r}=-0.01, p=0.95)$ or BPRS ( $\mathrm{r}=0.27, p=0.16)$ scores. Similarly, no significant correlations were found between serum levels of BDNF and either HAMD-17 $(\mathrm{r}=0.01, p=0.98)$ or BPRS $(\mathrm{r}=-0.01$, $p=0.96)$ scores after ECT. Changes in serum levels of BDNF were not significantly correlated with changes in the HAMD-17 $(\mathrm{r}=-0.08, p=0.69)$ or BPRS $(\mathrm{r}=0.15$, $p=0.42$ ) scores (Supplemental Table 3).

\section{Discussion}

To the best of our knowledge, this is the first study to examine whether BDNF is involved in the antidepressant effects of ketofol in ECT. The main findings included the 


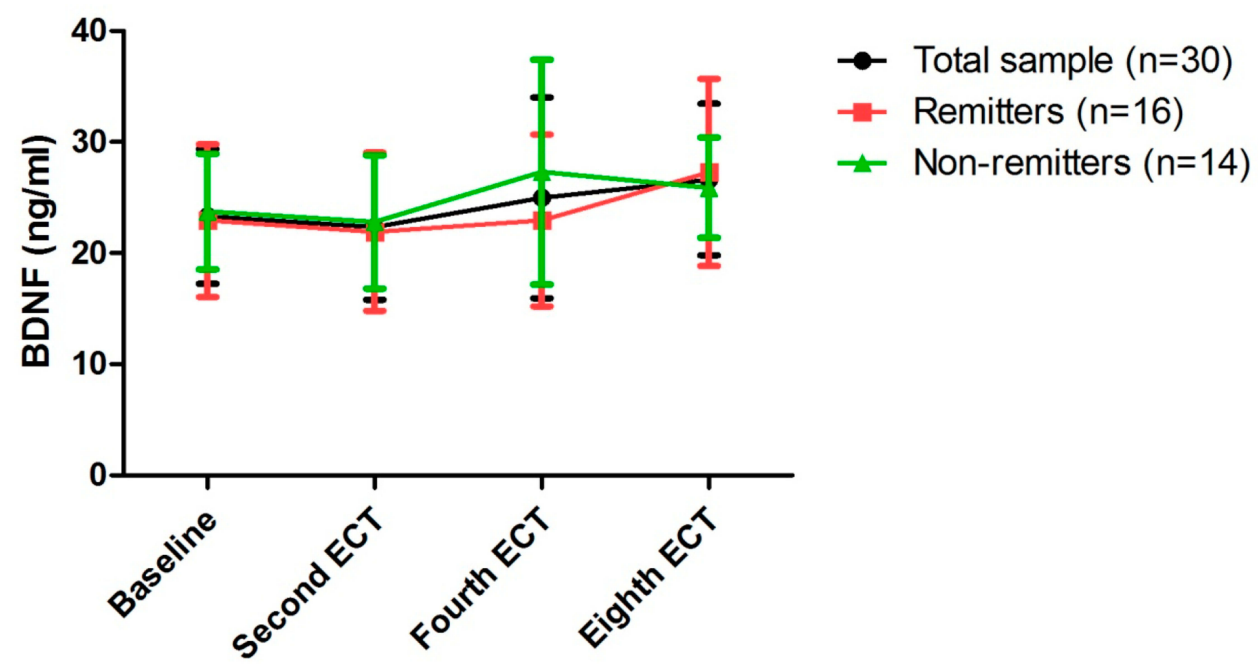

Figure 2 Change in serum levels of BDNF following eight ECT sessions in patients with treatment refractory depression.

Notes: No significant difference was found at any of the indicated times when compared to baseline across the total sample, even among remitters and non-remitters; no significant difference was found between remitters and non-remitters at any of the indicated times $(p<0.05)$.

Abbreviations: ECT, electroconvulsive therapy; BDNF, brain-derived neurotrophic factor.

following: 1) there were no significant differences in serum levels of BDNF between patients with TRD and healthy controls; 2) patients with TRD had a significant improvement in depressive and psychotic symptoms after the ECT course; 3) when compared to baseline, serum levels of BDNF showed no significant change at any time point across the entire sample, among both remitters and non-remitters; and 4) no significant association was found between serum levels of BDNF and the change in illness severity.

A perennial question among researchers is whether it is more correct to measure BDNF levels in plasma, serum or whole blood. BDNF is known to be stored in human platelets and to circulate in plasma, ${ }^{22}$ but BDNF concentration in plasma is affected by the handling of the blood sample, and it is released upon platelet degranulation. Thus, circulating BDNF is usually measured in the serum. For example, Naegelin et al found that BDNF levels can be reliably measured in human serum, and that these levels were quite stable over one year. ${ }^{23}$ Several meta-analyses have found reduced serum levels of BDNF in patients with MDD compared to healthy controls, ${ }^{24,25}$ suggesting a role of BDNF as a state-dependent biomarker of MDD. ${ }^{25}$ Notably, dissimilar classes of antidepressants ${ }^{26}$ or nonsteroidal anti-inflammatory drugs ${ }^{27}$ resulted in different regulation of serum BDNF concentrations. Thus, in this study patients with TRD were in a drug-free state during the period of ECT, focusing on the potential correlation between serum levels of BDNF and the antidepressant effects of ECT.
Numerous studies have investigated the effect of ECT on serum levels of BDNF in patients with MDD. ${ }^{22,28-33}$ Consistent with our findings, earlier studies also found that ECT could not alter serum levels of BDNF, despite decreasing depression severity. ${ }^{28-31,33,34}$ This indicates that ECT probably does not share a common mechanism of action as antidepressants in the improvement of depressive symptoms for patients with TRD.

Elevated $^{35}$ and decreased ${ }^{36}$ serum levels of BDNF have also been reported after ECT treatment. Changes in the plasma level of BDNF occur rapidly, and complete plasma/brain BDNF turnover takes approximately 6 min. $^{34,37}$ Thus, a possible explanation for this conflict could be attributed to the difference in the timing of blood sampling. Increases in serum levels of BDNF were found 5 weeks after starting $\mathrm{ECT}^{38}$ and during the treatment period; ${ }^{39,40}$ in other studies, the timing of the sampling varied from 1 day after ECT treatment to 1 month after the completion of ECT treatment. ${ }^{38-43}$ These findings indicated that increased serum levels of BDNF are not precocious but may take some time after completing the last ECT treatment.

In this study, a significant reduction in psychotic symptoms was found after ECT treatment. However, ketamine administered at a subanaesthetic dose could alleviate depressive symptoms in patients TRD within hours, ${ }^{44}$ and was associated with psychotomimetic effects, such as hallucinations. ${ }^{45}$ The most common side effects associated with ketamine are nausea, vomiting, dizziness, dysphoria, 
diplopia, drowsiness, and confusion. ${ }^{46,47}$ Ketamine is also contraindicated in those patients who have underlying conditions such as aortic dissection, uncontrolled hypertension, myocardial infarction or aneurysms, in which increased blood pressure would pose a risk of complications. $^{48,49}$ Thus, concerns persist with regard to the safety and feasibility of prolonged use of ketamine. ${ }^{44}$

The following limitations of the present study should be noted. First, the number of subjects was relatively small, partly explaining the negative results of this study. Second, all patients with TRD were hospitalized in a psychiatric hospital, limiting the generalizability of these findings to other facilities, such as outpatients facilities or the psychiatric wards of general hospitals. Third, none of the patients with TRD in this study were prescribed any antipsychotics or antidepressants during the study period, limiting the generalizability of these findings in clinical practice. Fourth, in this single-arm, open-label study the lack of a control group was another limitation due to the impact of subjective evaluation. Finally, data from the followup period were not collected, limiting our capacity to investigate whether it may take some time for serum levels of BDNF to increase after ECT treatment.

\section{Conclusion}

Our results indicate that serum levels of BDNF did not represent a suitable candidate biomarker for determining the antidepressant effects of ketofol during ECT for patients with TRD. Further studies with larger sample sizes are warranted to confirm these findings.

\section{Funding}

This study was funded by the Chinese National Science Foundation Project (81371506), the Guangzhou Science and technology Plan Project (201804010259), the Guangdong Provincial Science Foundation Project (2013040012414), the Science and Technology Plan Project of Liwan District, Guangzhou (201804011) and the Guangdong Provincial Science and Technology Project (2013B021800043).

\section{Disclosure}

The authors report no conflicts of interest in this work.

\section{References}

1. Petrides G, Fink M, Husain MM, et al. ECT remission rates in psychotic versus nonpsychotic depressed patients: a report from CORE. J ECT. 2001;17(4):244-253. doi:10.1097/00124509-20011 2000-00003
2. Zheng W, Li XH, Zhu XM, et al. Adjunctive ketamine and electroconvulsive therapy for major depressive disorder: a meta-analysis of randomized controlled trials. J Affect Disord. 2019;250:123-131. doi:10.1016/j.jad.2019.02.044

3. Wang X, Chen Y, Zhou X, Liu F, Zhang T, Zhang C. Effects of propofol and ketamine as combined anesthesia for electroconvulsive therapy in patients with depressive disorder. $J$ ECT. 2012;28 (2):128-132. doi:10.1097/YCT.0b013e31824d1d02

4. Yalcin S, Aydogan H, Selek S, et al. Ketofol in electroconvulsive therapy anesthesia: two stones for one bird. J Anesth. 2012;26 (4):562-567. doi:10.1007/s00540-012-1378-6

5. Chen J, Peng LH, Luo J, et al. Effects of low-dose ketamine combined with propofol on phosphorylation of AMPA receptor GluR1 subunit and GABAA receptor in hippocampus of stressed rats receiving electroconvulsive shock. J ECT. 2015;31(1):50-56. doi:10.1097/ YCT.0000000000000148

6. Altar CA, Whitehead RE, Chen R, Wortwein G, Madsen TM. Effects of electroconvulsive seizures and antidepressant drugs on brain-derived neurotrophic factor protein in rat brain. Biol Psychiatry. 2003;54(7):703-709. doi:10.1016/S0006-3223(03) 00073-8

7. Ryan KM, Dunne R, McLoughlin DM. BDNF plasma levels and genotype in depression and the response to electroconvulsive therapy. Brain Stimul. 2018;11(5):1123-1131. doi:10.1016/j. brs.2018.05.011

8. Molendijk ML, Spinhoven P, Polak M, Bus BA, Penninx BW, Elzinga BM. Serum BDNF concentrations as peripheral manifestations of depression: evidence from a systematic review and meta-analyses on 179 associations ( $\mathrm{N}=9484)$. Mol Psychiatry. 2014;19(7):791-800. doi:10.1038/mp.2013.105

9. Polyakova M, Stuke K, Schuemberg K, Mueller K, Schoenknecht P, Schroeter ML. BDNF as a biomarker for successful treatment of mood disorders: a systematic \& quantitative meta-analysis. $J$ Affect Disord. 2015;174:432-440. doi:10.1016/j.jad.2014.11.044

10. Brunoni AR, Lopes M, Fregni F. A systematic review and meta-analysis of clinical studies on major depression and BDNF levels: implications for the role of neuroplasticity in depression. Int J Neuropsychopharmacol. 2008;11(8):1169-1180. doi:10.1017/ S1461145708009309

11. Groves JO. Is it time to reassess the BDNF hypothesis of depression? Mol Psychiatry. 2007;12(12):1079-1088. doi:10.1038/sj.mp.4002075

12. Kurita M, Nishino S, Kato M, Numata Y, Sato T, Buch SJ. Plasma brain-derived neurotrophic factor levels predict the clinical outcome of depression treatment in a naturalistic study. PLoS One. 2012;7(6): e39212. doi:10.1371/journal.pone.0039212

13. Fond G, Loundou A, Rabu C, et al. Ketamine administration in depressive disorders: a systematic review and meta-analysis. Psychopharmacology. 2014;231(18):3663-3676. doi:10.1007/ s00213-014-3664-5

14. Kishimoto T, Chawla JM, Hagi K, et al. Single-dose infusion ketamine and non-ketamine N-methyl-d-aspartate receptor antagonists for unipolar and bipolar depression: a meta-analysis of efficacy, safety and time trajectories. Psychol Med. 2016;46(7):1459-1472. doi:10.1017/S0033291716000064

15. McGirr A, Berlim MT, Bond DJ, Fleck MP, Yatham LN, Lam RW. A systematic review and meta-analysis of randomized, double-blind, placebo-controlled trials of ketamine in the rapid treatment of major depressive episodes. Psychol Med. 2015;45(4):693-704. doi:10.1017/ S0033291714001603

16. Lepack AE, Fuchikami M, Dwyer JM, Banasr M, Duman RS. BDNF release is required for the behavioral actions of ketamine. Int J Neuropsychopharmacol. 2014;18(1):pyu033.

17. Zheng W, Zhou YL, Liu WJ, et al. Investigation of medical effect of multiple ketamine infusions on patients with major depressive disorder. J Psychopharmacol. 2019;33(4):494-501. doi:10.1177/ 0269881119827811 
18. Hamilton M. A rating scale for depression. $J$ Neurol Neurosurg Psychiatry. 1960;23(1):56-62. doi:10.1136/jnnp.23.1.56

19. Zhang M, Rosenheck R, Lin X, et al. A randomized clinical trial of adjunctive ketamine anesthesia in electro-convulsive therapy for depression. J Affect Disord. 2018;227:372-378. doi:10.1016/j. jad.2017.11.034

20. Overall JE, Beller SA. The Brief Psychiatric Rating Scale (BPRS) in geropsychiatric research: I. Factor structure on an inpatient unit J Gerontol. 1984;39(2):187-193. doi:10.1093/geronj/39.2.187

21. Zhan Y, Zhang B, Zhou Y, et al. A preliminary study of anti-suicidal efficacy of repeated ketamine infusions in depression with suicidal ideation. $J$ Affect Disord. 2019;251:205-212. doi:10.1016/j.jad. 2019.03.071

22. van Zutphen EM, Rhebergen D, van Exel E, et al. Brain-derived neurotrophic factor as a possible predictor of electroconvulsive therapy outcome. Transl Psychiatry. 2019;9(1):155. doi:10.1038/s41398019-0491-9

23. Naegelin Y, Dingsdale H, Säuberli K, Schädelin S, Kappos L, Barde Y-A. Measuring and validating the levels of brain-derived neurotrophic factor in human serum. Eneuro. 2018;5(2):1-9.

24. Kishi T, Yoshimura R, Ikuta T, Iwata N. Brain-derived neurotrophic factor and major depressive disorder: evidence from meta-analyses. Front Psychiatry. 2017;8:308. doi:10.3389/fpsyt.2017.00308

25. Sen S, Duman R, Sanacora G. Serum brain-derived neurotrophic factor, depression, and antidepressant medications: meta-analyses and implications. Biol Psychiatry. 2008;64(6):527-532. doi:10.1016/ j.biopsych.2008.05.005

26. Hellweg R, Ziegenhorn A, Heuser I, Deuschle M. Serum concentrations of nerve growth factor and brain-derived neurotrophic factor in depressed patients before and after antidepressant treatment. Pharmacopsychiatry. 2008;41(2):66-71. doi:10.1055/s-2007-1004 594

27. Ng QX, Ramamoorthy K, Loke W, et al. Clinical role of aspirin in mood disorders: a systematic review. Brain Sci. 2019;9(11):296. doi:10.3390/brainsci9110296

28. Lin CH, Chen M-C, Lee W-K, Chen -C-C, Huang C-H, Lane H-Y. Electroconvulsive therapy improves clinical manifestation with plasma bdnf levels unchanged in treatment-resistant depression patients. Neuropsychobiology. 2013;68(2):110-115. doi:10.1159/ 000352013

29. Fernandes B, Gama CS, Massuda R, et al. Serum brain-derived neurotrophic factor (BDNF) is not associated with response to electroconvulsive therapy (ECT): a pilot study in drug resistant depressed patients. Neurosci Lett. 2009;453(3):195-198. doi:10.1016/j. neulet.2009.02.032

30. Gedge L, Beaudoin A, Lazowski L, Du Toit R, Jokic R, Milev R. Effects of electroconvulsive therapy and repetitive transcranial magnetic stimulation on serum brain-derived neurotrophic factor levels in patients with depression. Front Psychiatry. 2012;3:12. doi:10.3389/ fpsyt.2012.00012

31. Gronli O, Stensland GO, Wynn R, Olstad R. Neurotrophic factors in serum following ECT: a pilot study. World J Biol Psychiatry. 2009;10 (4):295-301. doi:10.3109/15622970701586323

32. Sorri A, Jarventausta K, Kampman O, et al. Effect of electroconvulsive therapy on brain-derived neurotrophic factor levels in patients with major depressive disorder. Brain Behav. 2018;8(11):e01101. doi:10.1002/brb3.2018.8.issue-11

33. Rapinesi C, Kotzalidis GD, Curto M, et al. Electroconvulsive therapy improves clinical manifestations of treatment-resistant depression without changing serum BDNF levels. Psychiatry Res. 2015;227(2-3):171-178. doi:10.1016/j.psychres.2015.04.009
34. Machado-Vieira R, Yuan P, Brutsche N, et al. Brain-derived neurotrophic factor and initial antidepressant response to an N-methylD-aspartate antagonist. J Clin Psychiatry. 2009;70(12):1662-1666. doi: 10.4088/JCP.08m04659

35. Rocha RB, Dondossola ER, AnJ G, et al. Increased BDNF levels after electroconvulsive therapy in patients with major depressive disorder: a meta-analysis study. J Psychiatr Res. 2016;83:47-53. doi:10.1016/j.jpsychires.2016.08.004

36. Stelzhammer V, Guest PC, Rothermundt M, et al. Electroconvulsive therapy exerts mainly acute molecular changes in serum of major depressive disorder patients. Eur Neuropsychopharmacol. 2013;23 (10):1199-1207. doi:10.1016/j.euroneuro.2012.10.012

37. Pan W, Banks WA, Fasold MB, Bluth J, Kastin AJ. Transport of brain-derived neurotrophic factor across the blood-brain barrier. Neuropharmacol. 1998;37(12):1553-1561. doi:10.1016/S00283908(98)00141-5

38. Okamoto T, Yoshimura R, Ikenouchi-Sugita A, et al. Efficacy of electroconvulsive therapy is associated with changing blood levels of homovanillic acid and brain-derived neurotrophic factor (BDNF) in refractory depressed patients: a pilot study. Prog Neuropsychopharmacol Biol Psychiatry. 2008;32(5):1185-1190. doi:10.1016/j.pnpbp.2008.02.009

39. Bilgen AE, Bozkurt Zincir S, Zincir S, et al. Effects of electroconvulsive therapy on serum levels of brain-derived neurotrophic factor and nerve growth factor in treatment resistant major depression. Brain Res Bull. 2014;104:82-87. doi:10.1016/j.brainresbull.2014. 04.005

40. Marano CM, Phatak P, Vemulapalli UR, et al. Increased plasma concentration of brain-derived neurotrophic factor with electroconvulsive therapy: a pilot study in patients with major depression. J Clin Psychiatry. 2007;68(4):512-517. doi:10.4088/JCP.v68n0404

41. Piccinni A, Del Debbio A, Medda P, et al. Plasma brain-derived neurotrophic factor in treatment-resistant depressed patients receiving electroconvulsive therapy. Eur Neuropsychopharmacol. 2009;19 (5):349-355. doi:10.1016/j.euroneuro.2009.01.002

42. Bumb JM, Aksay SS, Janke C, et al. Focus on ECT seizure quality: serum BDNF as a peripheral biomarker in depressed patients. Eur Arch Psychiatry Clin Neurosci. 2015;265(3):227-232. doi:10.1007/ s00406-014-0543-3

43. Hu Y, Yu X, Yang F, et al. The level of serum brain-derived neurotrophic factor is associated with the therapeutic efficacy of modified electroconvulsive therapy in Chinese patients with depression. $J E C T$. 2010;26(2):121-125. doi:10.1097/YCT.0b013e3181c18bbf

44. Zheng W, Zhou YL, Liu WJ, et al. Rapid and longer-term antidepressant effects of repeated-dose intravenous ketamine for patients with unipolar and bipolar depression. $J$ Psychiatr Res. 2018;106:61-68. doi:10.1016/j.jpsychires.2018.09.013

45. Kurdi M, Theerth K, Deva R. Ketamine:current applications in anesthesia, pain, and critical care. Anesth Essays Res. 2014;8 (3):283-290. doi:10.4103/0259-1162.143110

46. Acevedo-Diaz EE, Cavanaugh GW, Greenstein D, et al. Comprehensive assessment of side effects associated with a single dose of ketamine in treatment-resistant depression. J Affect Disord. 2020;263:568-575. doi:10.1016/j.jad.2019.11.028

47. Ketalar (Ketamine Hydrochloride) Injection. U.S. Food \& Drug Administration; 2019.

48. Martinez V, Derivaux B, Beloeil H. Ketamine for pain management in France, an observational survey. Anaesth Crit Care Pain Med. 2015;34(6):357-361. doi:10.1016/j.accpm.2015.04.005

49. Han E, Kwon NJ, Feng LY, Li JH, Chung H. Illegal use patterns, side effects, and analytical methods of ketamine. Forensic Sci Int. 2016;268:25-34. doi:10.1016/j.forsciint.2016.09.001 


\section{Publish your work in this journal}

Neuropsychiatric Disease and Treatment is an international, peerreviewed journal of clinical therapeutics and pharmacology focusing on concise rapid reporting of clinical or pre-clinical studies on a range of neuropsychiatric and neurological disorders. This journal is indexed on PubMed Central, the 'PsycINFO' database and CAS, and is the official journal of The International Neuropsychiatric Association (INA). The manuscript management system is completely online and includes a very quick and fair peer-review system, which is all easy to use. Visit http://www.dovepress.com/testimonials.php to read real quotes from published authors. 